\title{
Erratum
}

\section{ERGODIC CAPACITY ANALYSIS FOR SIMO COGNITIVE FADING CHANNEL IN SPECTRUM SHARING ENVIRONMENT ${ }^{1}$}

\author{
Yang Yang Wang Jinlong Wu Qihui Liu Xin \\ (Institute of Communication Engineering, PLA University of Science and Technology, \\ Nanjing 210007, China)
}

\section{DOI $10.1007 / \mathrm{s} 11767-011-1003-0$}

The original online version of this article (Journal of Electronics (China), Vol. 27, No.5, September 2010, pp.677-685; DOI: 10.1007/s11767-011-0493-0) unfortunately contains mistakes in the right part of headers on Pages 678,680,682, and 684. The issue number and published month are wrong. The correct form should be No.5 September 2010. 